\title{
GAMBARAN PEMERIKSAAN VOLUME DARAH 1 cc DAN 3 cc DENGAN KONSENTRASI ANTIKOAGULAN EDTA TERHADAP KADAR HEMOGLOBIN DI KLINIK DEWI SARTIKA
}

\author{
Atna Permana, Zuraida, Siti Hadijah Sindarama \\ Program Studi Analis Kesehatan, Fakultas Kesehatan, Universitas Mohammad Husni Thamrin \\ Correspondence author: atnap@gmail.com, Jakarta, Indonesia
}

\begin{abstract}
ABSTRAK
Salah satu pemeriksaan laboratorium dalam mendiagnosis suatu penyakit adalah pemeriksaan hematologi (Dacie,J.V.;Lewis,S.M.,2001:12). Pemeriksaan hematologi rutin adalah jenis pemeriksan yang memberikan informasi tentang sel-se darah dan merupakan tes laboratorium yang paling umum dilakukan. Tujuan penelitian ini adalah Untuk mengetahui gambaran hasil kadar hemoglobin pada volume darah 1 dan 3 cc dengan menggunakan antikoagulan EDTA. Metode Penelitian ini adalah observasi sederhana yang dilakukan di Laboratorium Klinik. Metode pemeriksaan menggunakan hematology analyzer metode flowcytometer. Sampel dalam penelitian ini adalah mahasiswa tingkat akhir Prodi D3 Analis Kesehatan Universitas MH.Thamrin sejumlah 32 orang yang bersedia dijadikan responden. Hasil penelitian menunjukkan rata-rata kadar Hemoglobin (Hb) dengan spesimen darah EDTA $1 \mathrm{cc}$ rata-rata 11,91 gr/dl dengan kadar minimal 8,0 gr/dl dan maksimal 14,9 gr/dl sedangkan spesimen darah EDTA 3 cc rata-rata12,52 gr/dl dengan kadar minimal 8,2 gr/dl dan kadar maksimal 15,3 gr/dl. Kesimpulan dalam penelitian ini selisih kadar rata-rata darah EDTA $1 \mathrm{cc}(11,91 \mathrm{gr} / \mathrm{dl})$ dengan darah EDTA $3 \mathrm{cc}$ ( 12,52gr/dl ) adalah $0,61 \mathrm{gr} / \mathrm{dl}$, artinya ada perbedaan kadar hemoglobin $(\mathrm{Hb})$ yang diperiksa sebesar 0,61 dari nilai darah EDTA $1 \mathrm{cc}$ dengan $3 \mathrm{cc}$. Disarankan kepada petugas tenaga kesehatan agar menggunakan sesuai dengan yang ditetapkan dari pabrik.
\end{abstract}

Kata kunci $\quad$ EDTA, Hemoglobin, volume darah 1 dan $3 \mathrm{cc}$

\begin{abstract}
One of the laboratory tests in diagnosing a disease is a hematological examination (Dacie, J.V.; Lewis, S.M., 2001: 12). Routine hematology examination is a type of examination that provides information about blood cells and is the most commonly performed laboratory test. The purpose of this study was to describe the results of hemoglobin levels in blood volumes of 1 and $3 \mathrm{cc}$ using EDTA anticoagulants. This research method is a simple observation conducted in the clinical laboratory. The examination method uses a flowcytometer method hematology analyzer. The sample in this study were 32 students at the final level of D3 Health Analyst Study Program at MH Thamrin University who were willing to be respondents. The results showed that the average hemoglobin (Hb) level with the EDTA blood specimen $1 \mathrm{cc}$ was $11.91 \mathrm{~g} / \mathrm{dl}$ with a minimum level of $8.0 \mathrm{gr} / \mathrm{dl}$ and a maximum of $14.9 \mathrm{~g} / \mathrm{dl}$ while the EDTA blood specimen was $3 \mathrm{cc}$-Average $12.52 \mathrm{gr} / \mathrm{dl}$ with a minimum level of $8.2 \mathrm{~g} / \mathrm{dl}$ and a maximum level of $15.3 \mathrm{~g} /$ $\mathrm{dl}$. The conclusion in this study is that the difference between the average EDTA blood level of $1 \mathrm{cc}(11.91 \mathrm{gr} / \mathrm{dl})$ and EDTA blood $3 \mathrm{cc}(12.52 \mathrm{gr} / \mathrm{dl})$ is $0.61 \mathrm{~g} / \mathrm{dl}$, meaning that there is a difference in the hemoglobin $(\mathrm{Hb})$ level. examined for 0.61 from the EDTA blood value of $1 \mathrm{cc}$ by $3 \mathrm{cc}$. It is advisable for health workers to use according to what is specified from the factory.
\end{abstract}

Key words: EDTA, hemoglobin, blood volume 1 and $3 \mathrm{cc}$

Open Journal System (OJS): journal.thamrin.ac.id

http://journal.thamrin.ac.id/index.php/anakes/issue/view/35 


\section{PENDAHULUAN}

Pemeriksaan laboratorium merupakan pemeriksaan yang dilakukan untuk kepentingan klinik. Tujuan pemeriksaan laboratorium adalah untuk membantu menegakkan diagnosis penyakit pada penderita atau dapat digunakan untuk follow up terapi. sebelum hasil pemeriksaan laboratorium dikeluarkan haruslah diperhatikan secara memadai supaya dapat dicegah hasil yang tidak sesuai dengan keadaan penderita (Aulia,D.,2006:1).

Tahapan pra analitik pemeriksaan laboratorium diantaranya meliputi pengambilan spesimen dan penanganannya termasuk pemberian antikoagulan merupakan hal yang mutlak harus diperhatikan untuk mendapatkan hasil yang baik (Silman,E.;Wirawan,R.,2000:13).

Salah satu pemeriksaan laboratorium dalam mendiagnosis suatu penyakit adalah pemeriksaan hematologi (Dacie,J.V.;Lewis,S.M.,2001:12). Pemeriksaan hematologi rutin adalah jenis pemeriksan yang memberikan informasi tentang sel-se darah dan merupakan tes laboratorium yang paling umum dilakukan. pemeriksaan ini digunakan sebagai tes skrining yang luas untuk memeriksa gangguan seperti anemia,infeksi, dan banyak penyakit lainnya. (www.prodiakalimantan.com, 31/03/2011). Spesimen untuk pemeriksaan hematologi paling baik diambil dari darah vena dengan pemberian antikoagulan EDTA (ethylenediamine tetra-acetic acid) agar tidak membeku. EDTA umumnya tersedia dalam bentuk garam sodium (natrium ) atau pottasium (kalium) bertujuan untuk mencegah koagulasi dengan cara mengikat kalsium. EDTA memiliki keunggulan dibanding dengan antikoagulan yang lain yaitu tidak mempengaruhi sel-sel darah karena $\mathrm{pH}$ EDTA mendekati $\mathrm{pH}$ darah sehingga ideal untuk pengujian hematologi seperti pemeriksaan hemoglobin,hiung leukosit,hematokrit,laju endap darah,hitung trombosit,retikulosit,apusan darah dan sebagainya (Gandasoebrata,R.,2004:8). Berdasarkan penelitian Muslim,A.,dkk (2010:7) didapatkan hasil bahwa penggunaan $\mathrm{Na}_{2}$ EDTA yang berlebihan dapat mempengaruhi hasil pemeriksaan hematologi berupa penurunan nilai parameter hematologi dari nilai seharusnya. Pada penelitian ini dilakukan 2 perlakuan pemeriksaan dengan menggunakan spuit 5 cc dimana 2 tabung vakum masingmasing di isi darah 1 dan $3 \mathrm{cc}$. Perbandingan jumlah darah dengan antikoagulan yang dipakai harus tepat untuk menghindari kesalahan hasil pemeriksaan. Bila volume darah lebih banyak dari seharusnya maka darah akan membeku karena terdapat fibrin akan terjadi agregasi trombosit atau platelet clump dalam penampung yang akan menyebabkan hitung trombosit lebih rendah. Bila dipakai darah yang lebih sedikit sehingga antikoagulan yang ada berlebihan keadaan ini mengakibatkan eritrosit mengerut sehingga nilai hematokrit lebih rendah nilai MCV menurun dan MCHC meningkat sedangkan trombosit membesar dan mengalami desintegrasi (Dacie,J.V;Lewis, S.M.,2001:5). Dengan demikian ketepatan pemberian takaran EDTA dengan volume darah harus dengan benar diperhatikan (Nurrachmat,H.,2005:3).

Open Journal System (OJS): journal.thamrin.ac.id 
Berdasarkan latar belakang tersebut maka penulis ingin meneliti gambaran volume darah 1 dan $3 \mathrm{cc}$ dengan antikoagulan EDTA terhadap kadar hemoglobin.

\section{METODE}

Penelitian dilakukan di Laboratorium Klinik Dewi Sartika.Waktu penelitian Penelitian dilakukan dari bulan juni - agustus 2019.Populasi Seluruh mahasiswa tingkat akhir prodi analis kesehatan Universitas MH.Thamrin angkatan tahun 2016. Sampel Mahasiswa yang bersedia dijadikan responden pada penelitian ini berjumlah 32 orang spesimen darah diambil dari responden sebanyak $4 \mathrm{ml}$. endistribusikan darah ke dalam 2 buah tabung yang telah berisi antikoagulan EDTA masing masing 1 dan $3 \mathrm{cc}$. sampel dihomogenkan dengan rotator dan memeriksa sampel pada alat Rayto 7600. Melakukan pencatatan hasil yang didapat dan menganalisis data dengan tabel uji presentase untuk mengetahui gambaran volume darah dengan antikoagulan EDTA terhadap hasil kadar hemoglobin. Data penelitian yang terkumpul diolah dan disajikan dengan menggunakan tabel uji persentase.

\section{HASIL \& PEMBAHASAN}

Data hasil penelitian yang diperoleh dari 32 sampel mahasiswa Universitas MH.Thamrin di Laboratorium Klinik Dewi Sartika, Jakarta. Sampel adalah semua hasil pemeriksaan kadar hemoglobin yang keluar dari alat hematologi analyzer yang menggunakan antikoagulan EDTA dengan volume darah 1 dan $3 \mathrm{cc}$ tanpa membedakan umur dan jenis kelamin. Setelah dilakukan pemeriksaan terhadap gambaran kadar hemoglobin dengan pemberian antikoagulan EDTA terhadap volume darah 1 dan 3 cc didapatkan hasil:

Tabel 2

Hasil pemeriksaan kadar hemoglobin pada antikoagulan EDTA terhadap volume darah 1 dan 3 cc di laboratorium Klinik Dewi Sartika berdasarkan hasil maksimal dan minimal.

\begin{tabular}{lllll}
\hline Variabel & Maksimal & Minimal & Mean & SD \\
\hline $1 \mathrm{cc}$ & 14,9 & 8,0 & 11,91 & 1,4078 \\
\hline $3 \mathrm{cc}$ & 15,3 & 8,2 & 12,52 & 1,5431 \\
\hline
\end{tabular}

Berdasarkan tabel 1. Didapatkan hasil kadar hemoglobin pada antikoagulan EDTA dengan volume darah 1 cc dengan kadar minimal $8.0 \mathrm{gr} / \mathrm{dl}$ dan kadar maksimal 14,9 gr/dl, rata-rata 11,91 gr/dl sedangkan hasil kadar hemoglobin pada antikoagulan EDTA dengan volume darah $3 \mathrm{cc}$ dengan kadar minimal 8,2 gr/dl dan kadar maksimal 15,3 gr/dl, rata-rata 12,52 gr/dl.

Penelitian yang telah dilaksanakan pada bulan agustus 2019 di Laboratorium Klinik Dewi Sartika Jakarta dengan mengambil sampel darah vena mahasiswa tingkat VI Prodi D3 Analis Kesehatan Universitas 
MH.Thamrin sejumlah 32 mahasiswa tanpa membedakan umur dan jenis kelamin yang di periksa kadar hemoglobin dengan 2 perlakuan yang berbeda yaitu dengan menggunakan antikoagulan EDTA volume darah $1 \mathrm{cc}$ dan antikoagulan EDTA volume darah $3 \mathrm{cc}$ dan dari dua volume darah yang digunakan terdapat hasil yang cukup tipis antara keduanya.

Dari tabel 1 dinyatakan bahwa hasil kadar hemoglobin yang menggunakan antikoagulan EDTA volume darah $1 \mathrm{cc}$ dengan hasil minimal 8,0 gr/dl dan hasil maksimal 14,9 gr/dl, rata-rata 11,91 gr/dl sedangkan volume darah $3 \mathrm{cc}$ dengan hasil minimal 8,2 gr/dl dan hasil maksimal 15,3 gr/dl, rata-rata 12,52 gr/dl.

Dari hasil penelitian pemeriksaan hemoglobin yang menggunakan antikoagulan EDTA dengan volume darah 1 dan 3 cc menunjukkan ada perbedaan yaitu kadar maksimal 0,4gr/dl, kadar minimal 0,2 gr/dl, dan kadar rata-rata 0,61 gr/dl. Dimana penelitian ini menggunakan spuit $5 \mathrm{cc}$ dengan perlakuan membagi darah 1 cc dan 3 cc dalam 2 tabung vakum yang mengandung antikoagulan EDTA.

Hasil yang didapat dari pemeriksaan yang dilakukan di Laboratorium Klinik Dewi Sartika Jakarta terhadap hasil hemoglobin dengan menggunakan alat otomatis Hematology analyzer pada spesimen darah vena menggunakan antikoagulan EDTA dengan volume darah $1 \mathrm{cc}$ didapatkan kadar minimal 8,0 gr/dl dan maksimal 14,9 gr/dl, rata-rata (11,906 gr/dl). Apabila pemberian antikoagulan tidak sesuai, maka akan memberikan hasil yang tidak tepat. Jika dalam pemakaian antikoagulan kurang dari yang ditentukan darah dapat membeku sedangkan apabila pemakaian berlebih dari yang ditentukan akan menyebabkan eritrosit mengkerut dan sebaliknya jika konsentrasi antikoagulan yang digunakan lebih kecil dari konsentrasi yang ditentukan maka dapat menyebabkan eritrosit membesar (Dacie,J.V.;Lewis,S.M.,2001:5)

Sedangkan yang didapat dari pemeriksaan yang dilakukan di laboratorium Klinik Dewi Sartika jakarta, terhadap hasil hemoglobin dengan menggunakan alat otomatis analyzer pada sampel darah vena menggunakan antikoagulan EDTA dengan volume darah 3 cc didapatkan kadar minimal 8,2 gr/dl dan maksimal 15,3 gr/dl, rata-rata (12,52 gr/dl). Apabila pemberian antikoagulan EDTA dan volume darah sesuai maka akan memberikan hasil yang tepat Oleh sebab itu, lebih dianjurkan pemakaian antikoagulan EDTA dengan volume darah 3 cc karena sesuai dengan takaran. Jika dalam pemakaian antikoagulan kurang dari yang ditentukan darah dapat membeku sedangkan apabila pemakaian berlebih dari yang ditentukan akan menyebabkan eritrosit mengkerut dan sebaliknya jika konsentrasi antikoagulan yang digunakan lebih kecil dari konsentrasi yang ditentukan maka dapat menyebabkan eritrosit membesar. (Azhari Muslim, 2015).

Suhu penyimpanan sangat berpengaruh pada sampel pemeriksaan yang menggunakan darah EDTA sebaiknya segera dilakukan bila terpaksa ditunda dapat disimpan dalam lemari es $\left(4^{\circ}-6^{\circ}\right)$. Pada umumnya darah EDTA dapat disimpan 24 jam dalam lemari es. (Gandasoebrata,2007) tapi dalam penelitian ini digunakan suhu $37^{\circ} \mathrm{C}$. Penyimpanan darah EDTA pada suhu kamar yang terlalu lama dapat menyebabkan 
terjadinya perubahan pada eritrosit seperti pecahnya membran eritrosit (hemolisis) sehingga hemoglobin keluar ke medium sekelilingnya (plasma) yang menyebabkan terjadinya kenaikan kadar hemoglobin (Hilmi,2009).

Perlakuan sampel dalam proses pra analitik khususnya cara memasukan darah dari spuit ke dalam tabung harus benar-benar di perhatikan. Memasukan darah dengan cara disemprotkan akan berpotensi menyebabkan hemolisis. Memasukan darah ke dalam tabung dengan cara membuka jarum dan mengalirkannya pada dinding tabung sampai volume telah terpenuhi tidak akan menyebabkan hemolisis. (Joyce LeFever Kee,2007). Dan juga homogenisasi sampel yang tidak sempurna dapat menyebabkan hasil yang tidak tepat karena antara darah dan antikoagulan tidak sebanding. Setelah darah dimasukkan dalam tabung segera lakukan pencampuran atau homogenisasi dengan cara membolak-balikan tabung dengan lembut sebanyak 8 - 10 kali untuk menghindari penggumpalan trombosit dan pembentukan bekuan darah (Henrika,F.;Wulandari,D.;Setiabudy,R.,2011:4).

\section{SIMPULAN}

Hasil kadar rata-rata hemoglobin menggunakan volume darah $1 \mathrm{cc}(11,91 \mathrm{gr} / \mathrm{dl})$ dengan kadar minimal 8,0 gr/dl dan maksimal 14,9 gr/dl. Hasil kadar rata-rata hemoglobin menggunakan volume darah $3 \mathrm{cc}$ $(12,52 \mathrm{gr} / \mathrm{dl})$ dengan kadar minimal 8,2 gr/dl dan maksimal 15,3 gr/dl. Terdapat perbedaan kadar hemoglobin $(\mathrm{Hb})$ yang diperiksa dengan kadar maksimal 0,4 gr/dl, kadar minimal 0,2 gr/dl, dan kadar rata-rata 0,61 gr/dl dari nilai darah EDTA 1 cc dengan $3 \mathrm{cc}$.

\section{UCAPAN TERIMA KASIH}

Penulis mengucapkan terima kasihh kepada Prodi D III Analis Kesehatan Universitas MH Thamrin berperan serta dalam penelitian ini.

\section{DAFTAR PUSTAKA}

1. Aulia,A.,Wirawan,R.,Suherli,A., pengaruh lamanya penyimpanan darah dengan antikoagulan $\mathrm{K}_{2}$ EDTA dalam tabung vaccute terhadap beberapa parameter hematologi, majalah kedokteran indonesia, NO.52, hlm 9-11,januari,2002

2. BD Catalog. Venous blood collection tubes. [serial on internet]. 2011. [diakses 2 November 2011]. Available from ; http://catalog.bd.com/bdCat/viewProduct.doCustomer?product Number $=367859$

3. Fitria D.2014. perbedaan variasi volume darah dalam tabung vakutainer $\mathrm{K}_{2}$ EDTA 
4. Gandasoebrata,R., penuntun laboratorium klinik, dian rakyat, jakarta, 2004

5. https://dokumen.tips, documents

6. Idm.m.wikipedia.org./wiki/hemoglobin

7. International Council for Standardization of Haematology, 'Recomendation for EDTAanticoagulation of blood for Hematology Testing', American journal of clinical pathology, hlm 371-372,

8. Sabri L, Hastono ST. Statistik kesehatan. Rajagrafindo Persada. Jakarta. 2006.

9. Sacher RA, McPherson RA. Tinjauan klinis hasil pemeriksaan laboratorium. Ed.11. Terjemahan oleh Pendit BU, Wulandari D. EGC. Jakarta. 2004. hal. 2, 21, 41-43, 68, 673

10. Sastroasmoro, S.,Ismael,S., dasar-dasar metodologi penelitian klinis, sagung seto, jakarta, 2002

11. Tomodachi. Diktat hematologi. Fakultas Kedokteran. Universitas Hasanuddin. Makassar. 2004. hal. 9,42 .

12. Waterburry,L., Buku saku hematologi, edisi 3, santoso,H.A.,Suhandi,S.,Wijaya,S.W., (Eds), EGC, jakarta, 1998

13. Wirawan,R., pemantapan kualitas uji hematologi, Edisi 1, FKUI, jakarta, 2002 